\title{
O CULTIVO DO NIM INDIANO (Azadirachta indica A. JUSS.): UMA VISÃO ECONÔMICA
}

\author{
Alexandre Muzy Bittencourt ${ }^{1}$, Anadalvo Juazeiro dos Santos ${ }^{2}$, Vitor Afonso Hoeflich ${ }^{3}$, Ricardo Berger ${ }^{2}$ \\ ${ }^{1}$ Eng. Florestal, M.Sc., Doutorando em Engenharia Florestal, UFPR, Curitiba, PR, Brasil - alexbitten@ terra.com.br \\ ${ }^{2}$ Eng. Florestal, Dr., Depto. de Economia Rural e Extensão, UFPR, Curitiba, PR, Brasil - ajsantos@ufpr.br - berger@bighost.com.br \\ ${ }^{3}$ Eng. Agônomo, Dr., Depto. de Economia Rural e Extensão, UFPR, Curitiba, PR, Brasil - vitor.ufpr@ gmail.com \\ Recebido para publicação: 03/06/2008 - Aceito para publicação: 06/10/2008
}

\begin{abstract}
Resumo
O presente artigo tem como objetivo analisar a rentabilidade econômica do cultivo de nim em duas regiões produtoras, oeste do estado da Bahia e noroeste do estado de São Paulo. Os índices técnicos e os custos inerentes ao cultivo referem-se a plantios explorados em solos de boa produtividade e bem manejados e foram obtidos por meio da aplicação de questionários junto a produtores locais, fabricantes e comerciantes de produtos à base de nim. Três cenários foram analisados: 1) investimento no fator terra no início do cultivo; 2) arrendamento da terra; 3) sem considerar o fator terra. Planilhas eletrônicas foram utilizadas para análise dos custos, determinação da taxa interna de retorno do investimento e para a análise de sensibilidade. Esta última considerou a variação real dos preços do fruto de nim durante o período de 2002 a 2006, assim como variações percentuais nos custos totais de produção. Os plantios analisados em ambas as regiões foram considerados viáveis do ponto de vista econômico, com TIR variando de $15,18 \%$ a 28,32\% ao ano, quando comparadas à taxa mínima de atratividade de $12 \%$ ao ano. Entretanto, observou-se que os preços reais pagos ao produtor estão em declínio, o que pode, a continuar esse comportamento, inviabilizar novos investimentos na cultura nos próximos anos.
\end{abstract}

Palavras-chave: Nim; rentabilidade econômica.

\begin{abstract}
The cultivation of neem (Azadirachta indica A. Juss.): an economic vision. The present study has the objective of analyzing the economic yield of the Indian's neem cultivation in two producing regions, the west of the state of Bahia and the northwest of the state of São Paulo. The technical index and the costs related to the cultivation are referred to the cultivated plantations in good productivity and well managed soils and were obtained by the application of questionnaires to the local producers, companies and traders of neem based products. Three scenes had been so analyzed:1) Investment on the factor land, in the beginning of the cultivation; 2) Considering the lease of the land and 3) Without considering the factor land. Electronic spread sheets had been used to analyze the costs, to determine the Internal Rate of Return of the investment and as well as for the sensitivity analysis. This last has considered the real variation in prices of the fruit of neem during the period 2002 to 2006, as well as percentage changes in total production costs. The cultivation analyzed in both regions has been considered viable from the economic point of view, with IRR varying between $15,18 \%$ to $28,32 \%$ per year. However, it was observed that the real prices paid to the producer are decreasing, which can, if this behavior continues, turn new investments in this cultivation, not viable for the next few years.

Keywords: Neem; economical profitability.
\end{abstract}

\section{INTRODUÇÃO}

O nim (Azadirachta indica A. Juss.), árvore originária da Índia, tem sido cultivado nas regiões Norte, Nordeste, Sudeste e Centro-Oeste do Brasil. O principal produto dessa espécie é o óleo retirado das sementes, o qual contém inúmeros compostos ativos, sendo a azadiractina o mais importante deles (NEVES, 2004).

Essa espécie foi introduzida inicialmente no Brasil, por meio de sementes originárias das Filipinas, pelo Instituto Agronômico do Paraná (IAPAR), no ano de 1986, com o objetivo de se pesquisar 
a ação inseticida dessa planta. Mais tarde, em 1989 e 1990, esse mesmo Instituto obteve sementes provenientes da Índia, Nicarágua e República Dominicana, as quais foram plantadas, respectivamente, nas regiões de Londrina, Paranavaí (PR), Jaboticabal (SP) e Brasília (DF), para avaliação de desenvolvimento (MARTINEZ, 2002). Por possuir múltiplos usos, o nim tem atraído muita atenção e seus produtos têm sido cada vez mais utilizados na agricultura, pecuária, medicina e na fabricação de cosméticos. Praticamente todas as partes da planta são utilizáveis. Além das sementes, folhas, raízes e a madeira, também possui outros usos conhecidos (SHATURVEDI et al., 2004). Nesse sentido, Martinez (2002) afirma que os plantios orgânicos constituem-se na principal demanda por produtos isentos de agrotóxicos no mercado atual, e os produtos à base de nim, pela sua eficiência e baixa toxicidade ao homem e ao meio ambiente, atendem plenamente a essa demanda.

O presente artigo tem por objetivo analisar a rentabilidade econômica do cultivo do nim, assim como obter informações a respeito do mercado e da comercialização dos produtos dessa cultura em diferentes regiões do Brasil (EMBRAPA, 2005).

Um dos municípios estudados foi Barreiras, localizado no oeste do estado da Bahia. Essa região destaca-se por ser o maior produtor de grãos daquele estado e polo industrial da região. Além da produção de grãos, outras atividades têm crescido, como a fruticultura irrigada, considerada uma das melhores alternativas de uso para a agricultura irrigada no semiárido (SOUZA, 1990). Dentre as várias atividades, tem-se verificado o crescimento do cultivo do nim indiano com a finalidade de se obter o óleo utilizado como defensivo orgânico para o controle de pragas e doenças que atingem a agricultura e a pecuária. A outra região estudada foi o município de Catanduva e municípios vizinhos, localizados na região noroeste do estado de São Paulo. A produção de nim nessa região também cresce em função do consumo de insumos orgânicos para o controle de pragas e doenças de culturas agrícolas, como os citros e o café.

Entretanto, ainda é elevada a utilização de produtos químicos para o controle de pragas agrícolas, muitas vezes sem orientação técnica e de forma incorreta, causando sérios problemas ambientais (CODEVASF, 2005).

Em face da problemática ambiental do uso de agrotóxicos, há uma crescente demanda dos mercados nacional e internacional por alimentos orgânicos, a qual tem modificado o comportamento dos agricultores, que estão passando a se dedicar a formas mais eficientes de produção sem resíduos químicos, reduzindo assim a agressão ao meio ambiente. Aliado a isso, o aumento de resistência das pragas aos diversos tipos de pesticidas tem estimulado a busca por novas opções no controle de pragas e doenças na agricultura e na pecuária (EMATER-RN, 2006).

Desta forma, os Produtos Florestais Não-Madeireiros (PFNM), neste caso o óleo retirado das sementes de nim, surge como uma alternativa para o controle de um grande número de pragas e doenças.

No entanto, ao contrário da vasta bibliografia a respeito da biologia e das características inseticidas do nim, são poucos os estudos a respeito da viabilidade econômica da produção dessa espécie no Brasil e no mundo, fazendo com que o produtor rural não tenha acesso a informações confiáveis sobre a rentabilidade econômica dessa cultura. Nesse contexto, a presente pesquisa propõe contribuir acerca dos custos e rentabilidade econômica do cultivo do nim indiano.

\section{REVISÃO DE LITERATURA}

\section{Avaliação econômica de cultivos florestais}

Em um ambiente cada vez mais competitivo, os empreendimentos precisam de grandes esforços para manter os mercados e reduzir os custos, caso contrário, estarão fadados a desaparecer do mercado (THOROE, 1997). Dessa forma, antes de iniciar um novo empreendimento, faz-se necessário o levantamento de informações referente a receitas e custos, como mão-de-obra, terra e insumos, que irão compor o fluxo de caixa, com o qual se torna possível realizar a avaliação financeira correta do empreendimento, a fim de verificar sua viabilidade sob o ponto de vista econômico. Nesse sentido, Ross, Westerfield; Jaffe (2002) afirmam que determinar corretamente o fluxo de caixa ajuda o administrador financeiro a tomar melhores decisões.

De acordo com Graça; Mendes (1987), como parâmetros de avaliação financeira (rentabilidade) mais comumente utilizados estão o valor presente líquido (VPL), que fornece o valor futuro descontado para o presente em moeda corrente; a relação benefício/custo $(\mathrm{RB} / \mathrm{C})$, que mostra a relação proporcional entre benefícios e custos; e a taxa interna de retorno (TIR), que fornece a taxa de retorno intrínseca do sistema 
avaliado, a qual independe da taxa de desconto. A TIR serve como um parâmetro para avaliar se a taxa mínima de atratividade (TMA) remunera mais ou menos que o retorno da atividade. Entretanto, Berger e Padilha (2006) afirmam que, quando se tem um projeto ou uma única oportunidade de investimento, qualquer uma das medidas (TIR, VPL, RB/C) irá propiciar o mesmo resultado. Em essência, ao se aceitar o projeto pelo fato de que a TIR é maior que a TMA, o VPL é maior do que zero e a RBC será maior do que a unidade, ou seja, os parâmetros geram resultados congruentes entre si.

\section{Estudos de caso de avaliação econômica de empreendimentos com o nim indiano no Brasil e no mundo}

Xin; Wegener (2004) realizaram um amplo estudo com o intuito de determinar o potencial e a viabilidade econômica de uma indústria sustentável de nim na República Popular da China. Nesse país, a cada ano surgem novas áreas de plantios e poucas são as unidades processadoras existentes para a fabricação de produtos derivados do nim. Esses autores buscaram enfatizar a viabilidade econômica do estabelecimento de novos plantios e comprovar a agregação de valor que se obtém com o processamento do fruto e da folha pelas indústrias, principalmente na província de Yunnan, sul da China. Na avaliação econômica para implantação de novos plantios, obteve-se uma taxa interna de retorno (TIR) de 44,7\% ao ano, adotando-se uma taxa de desconto de $9,5 \%$ ao ano para um ciclo de 20 anos. A relação benefício/custo gerou o valor de 1,46, também apontando para um investimento viável do ponto de vista econômico. Para a análise da rentabilidade da indústria do processamento de nim, adotou-se uma taxa de desconto de $14,4 \%$ ao ano, a qual gerou um retorno do investimento de $117,3 \%$ para um horizonte de planejamento de 15 anos e uma relação benefício/custo de 1,57, também um investimento viável do ponto de vista econômico.

Outro estudo relevante quanto à avaliação econômica do nim foi realizado na Índia, no qual se adotou uma taxa de desconto de $12 \%$ ao ano para um ciclo de exploração de 23 anos. A relação benefício/custo foi de 3,59, e a taxa interna de retorno, de 45,9\%, avalizando o projeto como economicamente viável (NEEM FOUNDATION, 2005).

No Brasil, o único estudo relevante sobre avaliação econômica foi realizado por Falesi; Ferreira; Carvalho (2000), que estimaram a rentabilidade econômica do plantio de nim em uma propriedade rural no município de Castanhal (PA). O objetivo foi obter receitas a partir de folhas e frutos para uso medicinal e na fabricação de inseticidas. Os autores organizaram os custos para um hectare com 625 árvores em um espaçamento de $4 \mathrm{~m}$ x $4 \mathrm{~m}$. A avaliação econômica resultou em uma elevada taxa interna de retorno do investimento ( $265 \%$ ao ano).

\section{MATERIAL E MÉTODOS}

\section{Área de estudo}

O estudo abrangeu a região oeste do estado da Bahia, mais precisamente o município de Barreiras $\left(44^{\circ} 59^{\prime}\right.$ de longitude Oeste e $12^{\circ} 08^{\prime}$ de latitude Sul), fazendo divisa ao norte com o município de Rinchão das Neves e Formosa do Rio Preto, ao sul com o município de São Desidério e Baianópolis, a leste com o município de Catolândia e a oeste com o município de Luís Eduardo Magalhães. A outra região de estudo foi o noroeste do estado de São Paulo, sendo o município de Catanduva o polo regional de produção de nim. Esse município situa-se a uma latitude $21^{\circ} 08^{\prime} 16^{\prime \prime}$ Sul e a uma longitude $48^{\circ} 58^{\prime 2} 22^{\prime \prime}$ Oeste, fazendo divisa com os municípios de Tabapuã, Paraíso, Palmares Paulista, Ariranha, Pindorama, Itajobi, Ibirá, Urupês e Catiguá.

\section{Fonte de dados}

Os dados primários utilizados nesta pesquisa são relativos aos coeficientes técnicos, custos e receitas obtidos da implantação, condução e colheita da produção de plantios de nim indiano. Os dados foram obtidos por meio da aplicação de questionário junto a nove produtores de nim nas duas regiões visitadas. Como não se tem informações oficiais sobre a população de produtores nessas regiões, não foi possível a inferência estatística na análise, caracterizando assim a pesquisa como estudo de caso. Os preços médios dos insumos e dos produtos foram obtidos junto a empresas agropecuárias localizadas nas regiões visitadas, as quais foram identificadas anteriormente às visitas e quando da aplicação do questionário junto aos produtores rurais. 
A obtenção dos dados secundários constituiu-se de revisão de literatura referente ao assunto, elaborada a partir de títulos encontrados em bibliotecas de instituições paranaenses, baianas e paulistas, entre elas a Universidade Federal do Paraná (UFPR) - Setor de Ciências Agrárias e Curso de Engenharia Florestal -, o Instituto Agronômico do Paraná (IAPAR), a Faculdade São Francisco de Barreiras (FASB), a Empresa Brasileira de Pesquisa Agropecuária (EMBRAPA), a Empresa Baiana de Desenvolvimento Agropecuário (EBDA) e a Associação dos Agricultores Irrigantes da Bahia (AIBA). Instituições como o Instituto de Economia Agrícola (IEA), o Centro de Estudos Avançados em Economia Aplicada (CEPEA), o Instituto Brasileiro de Geografia e Estatística (IBGE), o Food and Agriculture Organization (FAO), o Instituto de Pesquisa Econômica Aplicada (IPEA), a Neem Foundation e o National Research Council, entre outras, foram consultadas a partir do acesso direto aos seus respectivos sites.

\section{Procedimento metodológico}

O instrumental de análise econômica utilizado baseou-se na determinação dos coeficientes técnicos de produção e no orçamento de custos e receitas que envolvem as atividades e operações realizadas no sistema de produção do nim indiano.

Utilizou-se a metodologia proposta por Graça et al. (2000), na qual se propõe a utilização de planilhas eletrônicas para a análise econômica de plantios florestais puros ou de sistemas agroflorestais com cultivos agrícolas. Elas foram utilizadas por se tratar de ferramentas de conhecimento público e de fácil acesso a produtores interessados em elaborar planilhas eletrônicas, além de ser eficiente para a análise proposta.

Por meio da utilização da taxa interna de retorno (TIR), um dos critérios mais tradicionais de avaliação de investimentos, pode-se analisar a rentabilidade econômica ou o retorno do investimento no cultivo do nim indiano nas duas regiões estudadas, oeste do estado da Bahia e o noroeste do estado de São Paulo.

O método da taxa interna de retorno requer o cálculo da taxa que zera o valor presente dos fluxos de caixa da alternativa analisada, sendo o investimento com a TIR maior que a taxa mínima de atratividade (TMA) considerada rentável e passível de investimento (CASSAROTO; KOPITTKE, 2000).

A taxa interna de retorno de um projeto é a taxa de retorno anual do capital investido, tendo a propriedade de ser a taxa de desconto que iguala o valor atual das receitas (futuras) ao valor atual dos custos (futuros) do projeto, ou seja, iguala o valor presente líquido a zero (REZENDE; OLIVEIRA, 2001). A fórmula é a seguinte:

$$
\mathrm{VPL} \sum_{t=0}^{n} \frac{R_{t}}{(1+T I R)^{t}}-\sum_{t=0}^{n} \frac{C_{t}}{(1+T I R)^{t}}=0
$$

Em que:

VPL = valor presente líquido.

TIR = taxa interna de retorno.

No presente estudo foi considerado 1 hectare de nim com um ciclo de produção de 15 anos e uma taxa de desconto (TMA) de $12 \%$ ao ano. Essa taxa, além de compatível com o perfil do pequeno e médio produtor das regiões, está embasada na literatura sobre estudos econômicos na área florestal, aproximando-se da aplicação do capital em fundos de investimentos disponíveis no mercado financeiro, como o fundo de renda fixa. Foram analisados três cenários:

- Cenário 1: considera-se o investimento no fator terra no início do cultivo.

- Cenário 2: considera-se o arrendamento da terra.

- Cenário 3: não se considera o fator terra na análise econômica.

Além da análise econômica, faz-se necessário verificar o quanto o projeto é sensível à variação em determinado fator, informação esta que pode orientar decisões e reduzir o risco do investimento. Dessa forma, Buarque ${ }^{1}$ (1991), citado por Ponciano; Mata; Costa (2004), comenta que a análise de sensibilidade consiste em medir em que magnitude uma alteração prefixada em um ou mais fatores do projeto altera o resultado final. Esse procedimento permite avaliar de que forma as alterações de cada uma das variáveis do projeto pode influenciar na rentabilidade dos resultados esperados. Cassaroto; Kopittke

${ }^{1}$ BUARQUE, C. Avaliação econômica de projetos. 6 ed. Rio de Janeiro: Campus, 1991. 266 p. 
(2000) afirmam que, quando uma pequena variação em um parâmetro altera drasticamente a rentabilidade de um projeto, o projeto é muito sensível a esse parâmetro.

Nesse sentido, o presente estudo de viabilidade econômica propõe a realização da análise de sensibilidade da TIR à variação real dos preços do fruto de nim durante o período de 2002 a 2006, assim como variações nos custos totais de produção em $10 \%, 20 \%, 30 \%, 40 \%$ e $50 \%$.

\section{RESULTADOS E DISCUSSÕES}

\section{Viabilidade econômica da produção do nim}

Fluxo de caixa - região noroeste do estado de São Paulo

A cultura do nim no noroeste paulista apresenta os maiores custos no primeiro ano de plantio e após o terceiro, quando se inicia a colheita dos frutos. Os custos a valores realizados do primeiro ano (ano zero), ou seja, de implantação, foram de $\mathrm{R} \$ 6.779,57$ por hectare, estando incluídos os custos da aquisição de mudas, preparo do solo, plantio, controle de plantas invasoras, adubação, impostos, assistência técnica e juros de custeio (Tabela1). Nos dois anos subsequientes, os valores diminuem para R $2.697,61$ e R\$ 2.925,88. A partir do terceiro ano ocorre um aumento no custo total por hectare em função, principalmente, do início da colheita dos frutos. Nesse ano, o custo total por hectare atinge $\mathrm{R} \$ 3.694,88$ e aumenta até o décimo ano, atingindo $\mathrm{R} \$ 7.681,16$. A partir do décimo primeiro ano esse valor reduz-se para $\mathrm{R} \$ 7.056,00$, permanecendo constante até o final do ciclo de 15 anos.

Tabela 1. Fluxo de caixa do cultivo do nim indiano na região noroeste do estado de São Paulo. Table 1. Cash flow from the cultivation of neem in the northwestern state of Sao Paulo.

\begin{tabular}{lccc}
\hline Ano & Custos totais/hectare & Receitas totais/hectare & Receitas líquidas/hectare \\
\hline 0 & $\mathrm{R} \$ 6.779,57$ & - & $-\mathrm{R} \$ 6.779,57$ \\
1 & $\mathrm{R} \$ 2.697,61$ & - & $-\mathrm{R} \$ 2.697,61$ \\
2 & $\mathrm{R} \$ 2.925,88$ & - & $-\mathrm{R} \$ 2.925,88$ \\
3 & $\mathrm{R} \$ 3.694,88$ & $\mathrm{R} \$ 2.856,00$ & $-\mathrm{R} \$ 838,88$ \\
4 & $\mathrm{R} \$ 4.202,72$ & $\mathrm{R} \$ 4.998,00$ & $\mathrm{R} \$ 795,28$ \\
5 & $\mathrm{R} \$ 6.498,14$ & $\mathrm{R} \$ 7.854,00$ & $\mathrm{R} \$ 1.355,86$ \\
6 & $\mathrm{R} \$ 6.381,02$ & $\mathrm{R} \$ 9.996,00$ & $\mathrm{R} \$ 3.614,98$ \\
7 & $\mathrm{R} \$ 7.056,50$ & $\mathrm{R} \$ 12.852,00$ & $\mathrm{R} \$ 5.795,50$ \\
8 & $\mathrm{R} \$ 7.056,50$ & $\mathrm{R} \$ 12.852,00$ & $\mathrm{R} \$ 5.795,50$ \\
9 & $\mathrm{R} \$ 7.056,50$ & $\mathrm{R} \$ 12.852,00$ & $\mathrm{R} \$ 5.795,50$ \\
10 & $\mathrm{R} \$ 7.681,16$ & $\mathrm{R} \$ 12.852,00$ & $\mathrm{R} \$ 5.170,84$ \\
11 & $\mathrm{R} \$ 7.056,50$ & $\mathrm{R} \$ 12.852,00$ & $\mathrm{R} \$ 5.795,50$ \\
12 & $\mathrm{R} \$ 7.056,50$ & $\mathrm{R} \$ 12.852,00$ & $\mathrm{R} \$ 5.795,50$ \\
13 & $\mathrm{R} \$ 7.056,50$ & $\mathrm{R} \$ 12.852,00$ & $\mathrm{R} \$ 5.795,50$ \\
14 & $\mathrm{R} \$ 7.056,50$ & $\mathrm{R} \$ 20.412,00$ & $\mathrm{R} \$ 5.795,50$ \\
15 & $\mathrm{R} \$ 7.056,50$ & $\mathrm{R} \$ 13.355,50$ \\
\hline
\end{tabular}

Fonte: Elaborado pelos autores, adaptado de Bittencourt (2006). Maiores informações acerca dos custos de implantação e manutenção do cultivo, consultar Bittencourt (2006).

Visando simplificar a composição dos custos de mão-de-obra, foi considerada, em cada operação florestal, a demanda de trabalhadores necessária para a sua realização, incluídos todos os encargos trabalhistas, tais como décimo terceiro salário, auxílio-doença, horas extras, abono de férias, fundo de garantia por tempo de serviço, previdência social e demais tributos.

$\mathrm{O}$ valor médio da terra nua para a região em um raio de $60 \mathrm{~km}$ do município de Catanduva, com acesso rodoviário de boa qualidade, foi pesquisado na região e posteriormente confirmado com dados do Instituto de Economia Agrícola (IEA), o qual realiza estudo sistemático de acompanhamento de preços de terras no estado de São Paulo. O valor médio considerado para a região levou em consideração o valor da terra nua (VTN) médio para a atividade de reflorestamento na região de Catanduva, sendo de R\$ $8.424,76 /$ hectare (IEA, 2005). Assim, para o cálculo do custo anual da terra ou custo de oportunidade da terra, foi utilizado o pagamento em espécie para a melhor alternativa agrícola apresentada na região quando da época de coleta de dados, ou seja, o arrendamento para a produção de cana-de-açúcar, no valor 
de $\mathrm{R} \$$ 687,28/ha (IEA, 2005). As informações contidas na tabela 1 e nas subsequentes referem-se ao cenário que considera o arrendamento da terra.

As receitas provenientes da produção do nim podem advir da comercialização das folhas, frutos e da madeira. Na região noroeste do estado de São Paulo não se verificou um comércio para as folhas do nim, fato que pode ser explicado por ser esta uma região que possui maior aptidão agrícola à pecuária, atividade que se configura como a maior consumidora de folhas de nim para incorporação na ração animal e também no controle de ectoparasitas, principalmente em bovinos. Dessa forma, a maior receita da cultura refere-se à comercialização do fruto, de cuja semente se extrai o óleo.

A produção dos frutos na região inicia-se no terceiro ano após o plantio e possui produção crescente até o presente momento, em que os plantios mais antigos contam com a idade de oito anos e produzem cerca de 6,5 toneladas de frutos por hectare/ano. O sistema de manejo adotado pelos produtores visitados é de 15 anos, com corte raso dos plantios ao final desse ciclo, com a venda da madeira. Esse manejo foi o considerado no presente trabalho, uma vez que inexistem trabalhos determinando manejos mais adequados para essa espécie. Sendo assim, uma vez que no Brasil os plantios são recentes e não existem estudos referenciando a evolução da produtividade do nim indiano em solos brasileiros, optou-se por adotar uma produção constante a partir do oitavo ano. Essa escolha está baseada na prudência em não superestimar a produção e consequentemente estimar retornos irreais à cultura analisada.

Considerando os aspectos anteriormente mencionados, a análise econômica deste estudo considerou que as futuras comercializações do fruto de nim para a região serão em quilograma $(\mathrm{kg})$, cujo valor médio pago aos produtores pela indústria consumidora dessa matéria-prima gira em torno de $\mathrm{R} \$$ 2,00 . No entanto, esse valor pode variar de $R \$ 1,50 / \mathrm{kg}$ a $\mathrm{R} \$ 2,50 / \mathrm{kg}$, de acordo com a qualidade da semente e o teor de umidade. Os valores pagos pelo fruto estão compatíveis com os valores registrados por Falesi; Ferreira; Carvalho (2000), de R $\$ 2,50 / \mathrm{kg}$.

Durante os três primeiros anos não há receitas, uma vez que as árvores ainda não entraram na fase madura de produção de frutos. A partir do terceiro ano inicia-se a produção de frutos, crescente até o oitavo ano e constante a partir deste até o final do ciclo. No entanto, quando descontamos essa receita a valor presente, o comportamento segue o exposto na tabela 1, pois quanto maior o período de tempo de uma série de pagamentos iguais (receitas nos diferentes anos) menor será seu valor presente.

Na região noroeste do estado de São Paulo ainda não há comércio de madeira de nim, visto que os plantios com maior idade possuem oito anos. No entanto, comenta-se sobre o alto valor da madeira, o

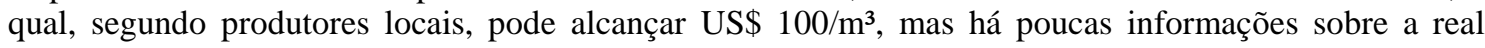
possibilidade de se atingir esse valor ao final do ciclo. Assim, a receita advinda da comercialização da madeira ao final do ciclo considerou o preço de mercado local de toras de Eucalyptus spp. em pé para a geração de energia, mercado este que certamente absorverá a madeira de nim pelo menos ao mesmo preço pago à madeira de eucalipto. O valor médio da madeira esteve em torno de $\mathrm{R} \$ 42,00 / \mathrm{m}^{3}$ para o mês de abril de 2006 (CEPEA, 2005).

Cabe ressaltar que a madeira de Nim possui características que a qualificam a competir com madeiras nobres, como a do mogno, também da família Meliaceae, o qual é protegido por lei impeditiva de corte. Entretanto, para o nim ainda não existe oferta suficiente de madeira que estabeleça uma demanda específica para madeira dessa espécie, não havendo assim um preço formado para sua comercialização. Outro fator que deve ser observado é que, na maioria dos plantios visitados na região, a poda não está sendo conduzida corretamente, para que se obtenha madeira de boa qualidade ao final do ciclo.

Fluxo de caixa - região oeste do estado da Bahia

A estrutura de custos do cultivo do nim indiano na região oeste do estado da Bahia (município de Barreiras) não difere em sua maioria das atividades desenvolvidas na mesma cultura no estado de São Paulo. Entretanto, algumas diferenças são importantes e merecem ser destacadas.

Dentre as principais diferenças na implantação e condução dessa cultura na Bahia, além de pequenas variações no preço de insumos, estão as relacionadas ao preço da terra, o qual é inferior à região noroeste de São Paulo. Não são realizadas algumas atividades de preparo do solo e na condução da cultura.

No preparo do solo não foi verificada a realização de gradagem niveladora. Na condução da cultura notou-se a não realização de podas, sendo mencionado pelos participantes da pesquisa que não seria necessário, uma vez que se pretende principalmente conduzir a espécie para produção de folhas e frutos, restando ao final do ciclo uma renda adicional com a venda da madeira para fins energéticos ao preço de $\mathrm{R} \$ 40,00 / \mathrm{m}^{3}$ em pé. Existe um mercado consumidor de madeira de eucalipto na região para a produção de carvão, e sendo o nim uma espécie com características energéticas interessantes, ele deverá concorrer em iguais condições com a madeira de eucalipto na região. 
$\mathrm{O}$ custo de arrendamento da terra na região considerou o pagamento em função da melhor alternativa para o uso da terra, no caso a soja, uma vez que as áreas utilizadas para a análise são classificadas como terciárias ${ }^{2}$ para esse cultivo, o qual propicia o pagamento de 2,8 sacas de 60 $\mathrm{kg} /$ hectare/ano. Esse valor convertido a valores monetários com o preço da saca de soja médio pago ao produtor em Barreiras, de $\mathrm{R} \$ 22,50 / \mathrm{sc}$, atinge $\mathrm{R} \$ 63,00 / \mathrm{ha} / \mathrm{ano}$.

$\mathrm{Na}$ cultura do nim no oeste baiano, os maiores custos também ocorrem no primeiro ano de plantio (Tabela 2).

Tabela 2. Fluxo de caixa do cultivo do nim indiano na região oeste do estado da Bahia.

Table 2. Cash flow from the cultivation of Indian neem in the western region of Bahia state.

\begin{tabular}{lccc}
\hline Ano & Custos totais/hectare & Receitas totais/hectare & Receitas líquidas/hectare \\
\hline 0 & $\mathrm{R} \$ 6.064,33$ & - & $-\mathrm{R} \$ 6.064,33$ \\
1 & $\mathrm{R} \$ 2.839,72$ & $\mathrm{R} \$ 720,00$ & $-\mathrm{R} \$ 2.119,72$ \\
2 & $\mathrm{R} \$ 3.225,22$ & $\mathrm{R} \$ 864,00$ & $-\mathrm{R} \$ 2.361,22$ \\
3 & $\mathrm{R} \$ 3.555,25$ & $\mathrm{R} \$ 3.570,00$ & $\mathrm{R} \$ 14,75$ \\
4 & $\mathrm{R} \$ 3.890,82$ & $\mathrm{R} \$ 4.998,00$ & $\mathrm{R} \$ 1.107,18$ \\
5 & $\mathrm{R} \$ 5.563,01$ & $\mathrm{R} \$ 9.282,00$ & $\mathrm{R} \$ 3.718,99$ \\
6 & $\mathrm{R} \$ 5.238,51$ & $\mathrm{R} \$ 10.710,00$ & $\mathrm{R} \$ 5.471,49$ \\
7 & $\mathrm{R} \$ 6.078,75$ & $\mathrm{R} \$ 14.280,00$ & $\mathrm{R} \$ 8.201,25$ \\
8 & $\mathrm{R} \$ 6.078,75$ & $\mathrm{R} \$ 14.280,00$ & $\mathrm{R} \$ 8.201,25$ \\
9 & $\mathrm{R} \$ 6.078,75$ & $\mathrm{R} \$ 14.280,00$ & $\mathrm{R} \$ 8.201,25$ \\
10 & $\mathrm{R} \$ 6.740,72$ & $\mathrm{R} \$ 14.280,00$ & $\mathrm{R} \$ 7.539,28$ \\
11 & $\mathrm{R} \$ 6.078,75$ & $\mathrm{R} \$ 14.280,00$ & $\mathrm{R} \$ 8.201,25$ \\
12 & $\mathrm{R} \$ 6.078,75$ & $\mathrm{R} \$ 14.280,00$ & $\mathrm{R} \$ 8.201,25$ \\
13 & $\mathrm{R} \$ 6.078,75$ & $\mathrm{R} \$ 14.280,00$ & $\mathrm{R} \$ 8.201,25$ \\
14 & $\mathrm{R} \$ 6.078,75$ & $\mathrm{R} \$ 21.480,00$ & $\mathrm{R} \$ 8.201,25$ \\
15 & $\mathrm{R} \$ 6.078,75$ & $\mathrm{R} \$ 15.401,25$ \\
\hline
\end{tabular}

Fonte: Elaborado pelos autores, adaptado de Bittencourt (2006).

No segundo e terceiro anos, o custo é maior em relação aos custos desse mesmo período no estado de São Paulo em função da colheita de folhas durante a fase não produtiva de frutos. No presente estudo, os custos a valores realizados do ano de implantação (ano zero) e dois anos subsequentes foram, respectivamente, de $\mathrm{R} \$ 6.064,33, \mathrm{R} \$ 2.839,72$ e $\mathrm{R} \$ 3.225,22$ por hectare (Tabela 2). No primeiro valor estão incluídos os custos da aquisição de mudas, do preparo do solo, do plantio e do controle de plantas invasoras. A partir do terceiro ano ocorre um aumento no custo total por hectare em função do início da colheita dos frutos. No terceiro ano, o custo total por hectare atinge R $\$ 3.555,25$ e apresenta tendência de aumento até o décimo ano, chegando a $\mathrm{R} \$ 6.740,72$. A partir desse ano, o valor permanece constante até o final do ciclo de 15 anos, em $\mathrm{R} \$ 6.078,75$.

Outra diferença importante entre as duas regiões analisadas está no valor médio da terra nua para a região de Barreiras (BA), o qual é consideravelmente menor se comparado à região noroeste de São Paulo. Tal preço foi pesquisado nessa região durante as visitas e posteriormente confirmado junto ao Instituto Nacional de Colonização e Reforma Agrária (INCRA), instituto que realiza periodicamente o acompanhamento de preços de terra em todo o território nacional. $\mathrm{O}$ valor considerado para a região oeste da Bahia baseou-se no valor da terra nua (VTN) para o cultivo de nim em áreas terciárias de soja, cotadas em sacas de soja. O valor máximo de terras classificadas pelo INCRA como áreas terciárias de soja está cotado em 20 sacas de $60 \mathrm{~kg} / \mathrm{ha}$; sendo o valor médio da saca $\mathrm{R} \$ 22,50$, tem-se o valor de $\mathrm{R} \$ 450,00 / \mathrm{ha}$.

No oeste baiano existem cerca de seis milhões de hectares de cerrado, dos quais mais de quatro milhões são agricultáveis. Destes, cerca de três milhões de hectares permanecem com potencial de exploração. Ainda existem terras que não são classificadas para uso agrícola, como vales, caatinga e cerradão. Essas tipologias não alcançam o valor de 10 sacas de soja por hectare.

A grande diferença entre as regiões noroeste do estado de São Paulo e oeste da Bahia está na estrutura de receitas e no mercado consumidor dos produtos oriundos dessa cultura. Em ambas as regiões os

\footnotetext{
2 Áreas terciárias são áreas consideradas menos produtivas para uso agrícola convencional, como a soja, possuindo, assim, preços menores quando comparadas às áreas secundárias e primárias.
} 
produtores manejam o nim para a produção do fruto como produto principal e para a produção de madeira ao final do ciclo como uma renda extra. No oeste da Bahia, além do fruto, existe ainda a exploração da folha durante o período não produtivo de frutos. A receita dessa última auxilia o produtor a reduzir a receita líquida negativa do início do cultivo. $\mathrm{O}$ quilo da folha é comercializado localmente a $\mathrm{R} \$ 1,20$, e seu principal uso é como vermífugo para o gado. A folha primeiramente é seca, triturada e incorporada à ração animal. Também é utilizada no controle de ectoparasitos em animais, principalmente em bovinos.

A produção de folhas inicia-se ao segundo ano da cultura, com extração de $1.000 \mathrm{~kg} / \mathrm{ha}$, passando para $1.200 \mathrm{~kg} / \mathrm{ha}$ no terceiro ano. Esse é o volume bruto por hectare, sendo que o volume final comercializado após a secagem é de $60 \%$ da quantidade inicial. Ainda não existem estudos que indiquem a quantidade máxima que deve ser retirada da planta para que não haja problemas quanto ao seu desenvolvimento. No entanto, problemas dessa espécie não ocorrem nas áreas estudadas.

A produção dos frutos na região inicia-se no terceiro ano e tem uma produtividade um pouco superior aos plantios no estado de São Paulo, chegando a produzir cerca de 7,2 toneladas de frutos no oitavo ano. Assim como para o estado de São Paulo, na região oeste do estado da Bahia ainda não existem plantios com mais de oito anos para se comparar e até realizar uma possível prognose da produção, sendo esta considerada constante a partir do oitavo ano. Essa opção torna-se mais sensata, uma vez que se deseja avaliar a rentabilidade da cultura evitando estabelecer retornos irreais ao produtor com base em uma possível produção futura. Parte-se do pressuposto de que a produção dificilmente tenderá a cair com o passar dos anos, pois existem plantios de nim na África com idades acima de 23 anos e com produção crescente. O preço do fruto é comercializado em média a $R \$ 2,00 / \mathrm{kg}$, podendo variar de $\mathrm{R} \$ 1,90$ a $\mathrm{R} \$$ 2,30/kg em função da qualidade do fruto.

\section{Viabilidade econômica dos cenários propostos}

De maneira geral, todos os cenários apresentaram-se viáveis sob o ponto de vista de análise de investimentos quando comparados à taxa mínima de atratividade de $12 \%$ ao ano utilizada, conforme pode ser observado na tabela 3. Na região noroeste de São Paulo, o retorno econômico da atividade apresentouse menor dentre os cenários propostos quando comparado à região oeste da Bahia. Isso se deve principalmente a dois fatores: elevado preço da terra na região paulista que chega a ser até $95 \%$ superior às terras cultivadas com nim no oeste baiano e também devido a variações no fluxo de receitas da cultura nesta última região. Apesar de se analisar cenários com o mesmo horizonte de planejamento nas duas regiões, comparações devem ser realizadas com ressalvas, uma vez que são regiões bastante distintas em termos econômicos e edafoclimáticos.

Tabela 3. Rentabilidade econômica do cultivo do nim nas regiões noroeste de São Paulo e oeste da Bahia em 2006.

Table 3. Profitability of the economic cultivation of neem in the northwest of Sao Paulo and west of Bahia in 2006.

\begin{tabular}{lccc}
\hline Região & $\begin{array}{c}\text { Cenário 1* } \\
\text { TIR }(\boldsymbol{\%})\end{array}$ & $\begin{array}{c}\text { Cenário 2* } \\
\text { TIR (\%) }\end{array}$ & $\begin{array}{c}\text { Cenário 3* } \\
\text { TIR (\%) }\end{array}$ \\
\hline Noroeste de São Paulo & 15,2 & 18,5 & 23,6 \\
Oeste da Bahia & 27,1 & 27,4 & 28,3 \\
\hline
\end{tabular}

Fonte: Elaborado pelos autores, adaptado de Bittencourt (2006). *: Cenário 1: considera o investimento no fator terra no início do cultivo; Cenário 2: considera o arrendamento da terra; Cenário 3: não considera o fator terra na análise econômica.

A análise realizada para a região oeste do estado da Bahia apresentou elevado retorno econômico, variando pouco entre os cenários propostos muito em função do baixo preço da terra, que pouco afetou a estrutura de custos da cultura. Já a região noroeste de São Paulo, apesar de apresentar resultados inferiores em termos de retorno econômico, apresenta uma melhor infraestrutura, contando com uma indústria que processa o fruto do nim para extração do óleo e que compra toda a produção regional, o que propicia ao produtor rural uma segurança maior quando da época de colheita e comercialização da produção.

\section{Análise de sensibilidade dos cenários propostos}

Com o objetivo de se testar a viabilidade econômica da cultura em cenários pessimistas e otimistas, realizaram-se variações nos preços pagos pelo quilograma do fruto de nim e nos custos totais de produção. Com base nessas variações foi realizada uma análise de sensibilidade, a fim de determinar o 
comportamento da taxa interna de retorno a essas variações. Cabe lembrar que essa análise de sensibilidade a preços e a custos refere-se exclusivamente à estrutura de custos de um hectare proposta e que os produtores participam de uma estrutura de mercado próxima de uma concorrência pura e perfeita, na qual não possuem poder de mercado para influenciar o preço, os quais são conhecidos na literatura por "pricetaker", ou seja, tomadores de preço, e que em situações normais comercializam toda sua produção. A única maneira de aumentar o retorno da cultura é ganhando escala de produção, possibilitando assim obter uma redução nos custos fixos. Dessa forma, a análise de sensibilidade ora apresentada procura tão somente saber o quão robusta (limite ainda viável economicamente) é a estrutura de produção quando submetida a variações de preços e custos totais de produção.

Sensibilidade ao preço - região noroeste do estado de São Paulo

De acordo com produtores das regiões noroeste de São Paulo, oeste da Bahia e empresas consultadas em diversas regiões do país, os preços do quilo do fruto variaram em termos reais de $\mathrm{R} \$$ 2,78/ $\mathrm{kg}$ a R \$2,00/kg durante o período de 2002 a 2006, gerando um decréscimo anual de 9,4\% nos níveis de preços pagos aos produtores. Adotou-se essa tendência de queda de preço para se avaliar o impacto na TIR da cultura caso esse processo de redução do preço do quilo do fruto permaneça pelos próximos quatro anos. Da mesma forma, também foi realizada uma sensibilidade considerada otimista, ou seja, com aumento dos preços nas mesmas variações propostas para os próximos quatro anos.

A análise de sensibilidade realizada na presente pesquisa refere-se ao cenário que considera o arrendamento da terra para o cultivo do nim. Optou-se por analisar somente um cenário, já que o comportamento da TIR ao aumento ou redução do preço do fruto ou dos custos de produção será o mesmo entre os cenários, diferindo apenas na magnitude da variação. Entretanto, essa análise deve ser considerada quando da análise do investimento, mas dispensada aqui para não tornar a leitura repetitiva. Os preços da madeira para ambas as regiões estudadas, e das folhas especificamente para a região oeste da Bahia, foram considerados constantes na análise de sensibilidade, ou seja, variou-se apenas o valor do quilo do fruto, a principal fonte de receitas da cultura.

Na região noroeste do estado de São Paulo, a taxa interna de retorno (TIR) mostrou-se fortemente afetada quando realizada a variação de preço proposta, ou seja, quanto maior for a tendência de queda de preços, menor será o retorno do investimento na cultura (Figura 1). Sendo assim, permanecendo-se a tendência de queda de preços e mantendo-se inalterada a atual estrutura de custos, o cultivo do nim indiano poderá tornar-se inviável até 2008 , considerada a taxa mínima de atratividade de $12 \%$ ao ano. A figura 1 apresenta a variação da taxa interna de retorno em resposta à variação nos níveis de preço.

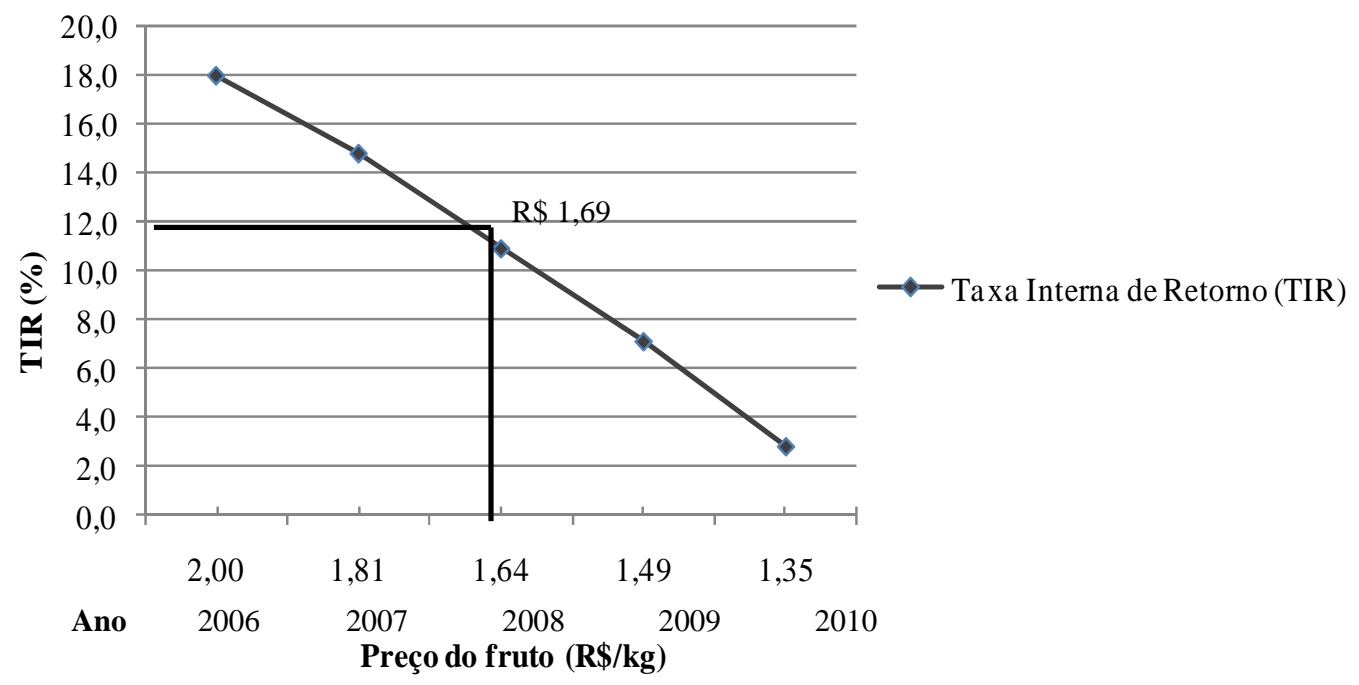

Fonte: Elaborado pelos autores

Figura 1. Sensibilidade da TIR à redução nos níveis de preço do fruto seco - plantios de nim na região noroeste do estado de São Paulo.

Figure 1. IRR sensitivity of the reduction in the levels of price of the nut - neem plantations in the northwestern state of Sao Paulo. 
Pela análise de sensibilidade, nota-se que, permanecendo constantes os custos e reduzindo-se apenas o preço do quilograma do fruto, a cultura permanece viável até o preço de $\mathrm{R} \$ 1,69 / \mathrm{kg}$, quando comparado à TMA de $12 \%$ ao ano adotada como retorno mínimo para aceitar investimento na cultura do nim indiano.

Já quando se realizam aumentos nos níveis de preços do fruto, a cultura torna-se mais atrativa ao produtor e a novos investimentos.

A figura 2 apresenta a sensibilidade da taxa interna de retorno em função do aumento nos níveis de preço do quilo do fruto seco para a região noroeste do estado de São Paulo.

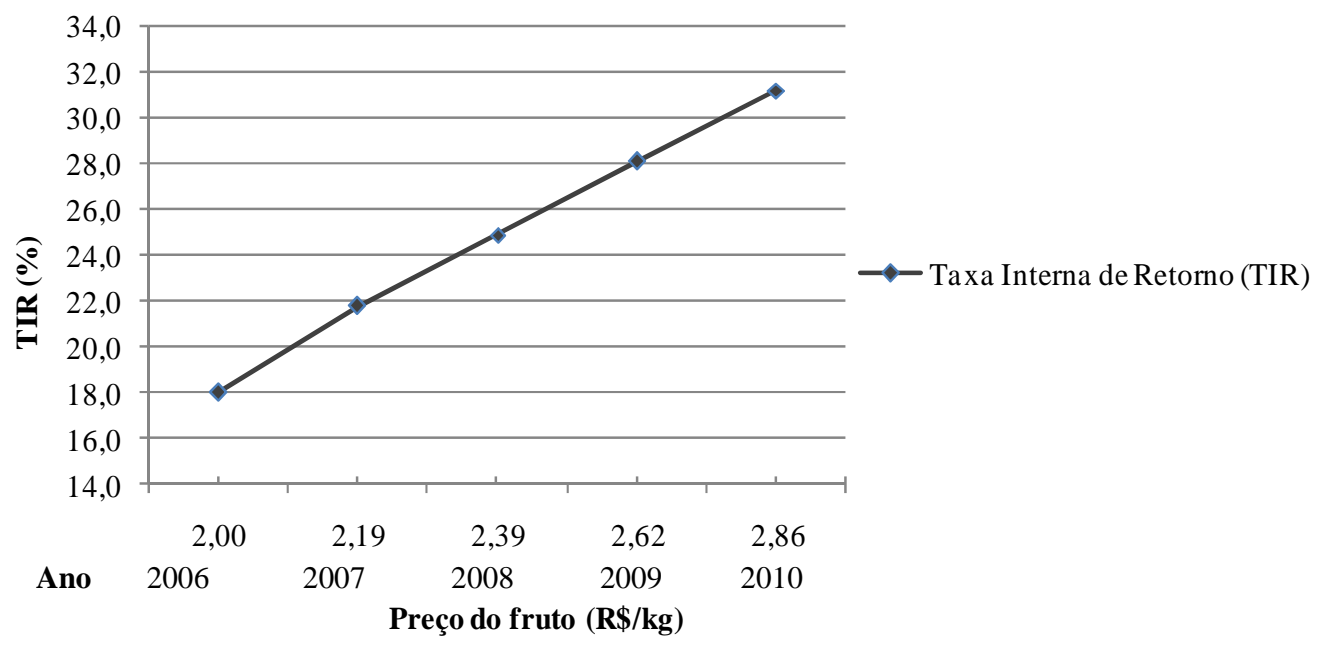

Fonte: Elaborado pelos autores.

Figura 2. Sensibilidade da TIR ao aumento nos níveis de preço do fruto seco - plantios de nim na região noroeste do estado de São Paulo.

Figure 2. IRR sensitivity of the increase in the levels of price of the nut - neem plantations in the northwestern state of Sao Paulo.

Nessa situação otimista, ocorre um aumento na taxa interna de retorno (TIR) do cultivo do nim indiano na região noroeste de São Paulo. Já em 2007, considerando um aumento de 9,4\% no preço do quilo do fruto e permanecendo constantes os custos de produção, a TIR sobe para $22 \%$ ao ano (Figura 2).

Sensibilidade ao preço - região oeste do estado da Bahia

A análise de sensibilidade a variações nos preços realizada para a região oeste do estado da Bahia mostra que a viabilidade econômica do cultivo nessa região é menos afetada a tais variações em relação à região noroeste de São Paulo. Isso se deve principalmente ao menor valor da terra no oeste baiano. Outro fator importante é a comercialização das folhas durante o período não produtivo de frutos da planta, a qual possibilita uma redução da receita líquida negativa do início da produção. Somado ao melhor aproveitamento do potencial da espécie com a exploração de folhas e madeira, ainda há uma maior produtividade de frutos contribuindo para o aumento das receitas no decorrer do ciclo analisado.

A figura 3 apresenta a sensibilidade-preço, que apresenta a oscilação da taxa interna de retorno quando se reduz o nível de preço do fruto pago ao produtor rural na região oeste do estado da Bahia.

É possível visualizar, por meio da figura 3, que para a região oeste da Bahia o preço pode decrescer até $\mathrm{R} \$ 1,31 / \mathrm{kg}$ em 2010 que a cultura continua viável, com uma TIR de $12 \%$ ao ano. A partir desse nível de preço, mantendo-se a atual estrutura de custos e a tendência de queda real nos níveis de preço do quilo do fruto, a cultura passa a ser inviável quando comparada à TMA de $12 \%$ ao ano. A Figura 4 apresenta a variação nos preços supondo que eles aumentem nos próximos anos na mesma proporção anteriormente descrita. 
Como já se esperava, a taxa interna de retorno aumenta proporcionalmente ao aumento do preço do quilo do fruto do nim. Dessa forma, uma pequena variação positiva de $9,4 \%$ no preço do fruto eleva o retorno da atividade para 30,5\% ao ano, mantendo-se a atual estrutura de custos.

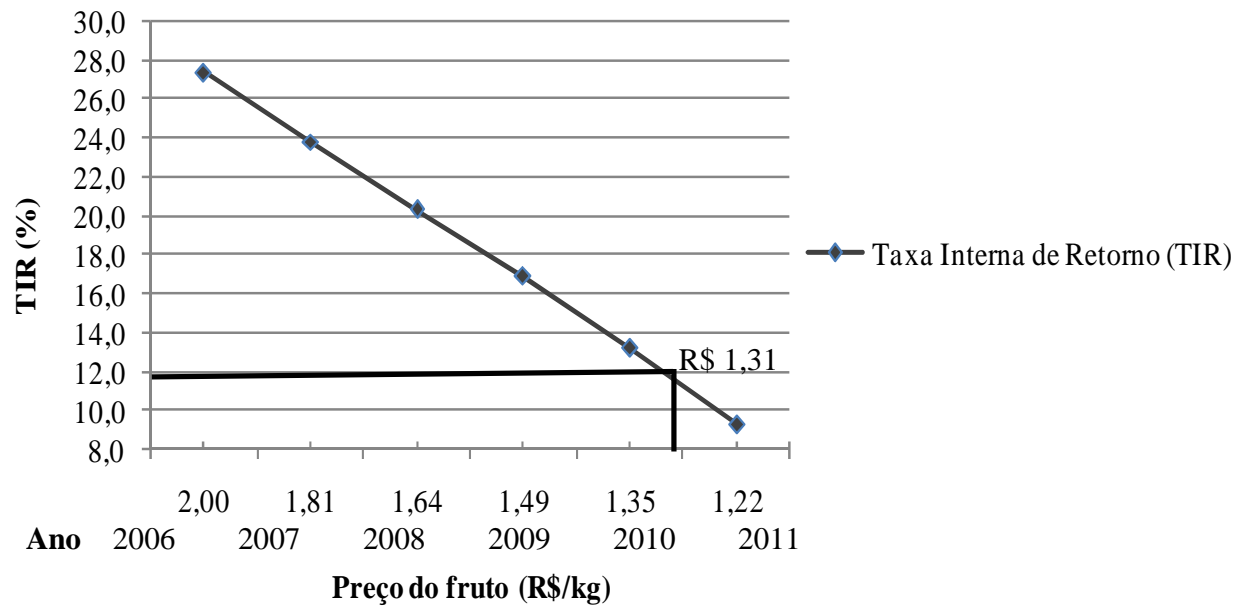

Fonte: Elaborado pelos autores.

Figura 3. Sensibilidade da TIR à redução nos níveis de preço do fruto seco - plantios de nim na região oeste do estado da Bahia.

Figure 3. IRR sensitivity of the reduction in the levels of price of the nut - neem plantations in the western region of Bahia state.

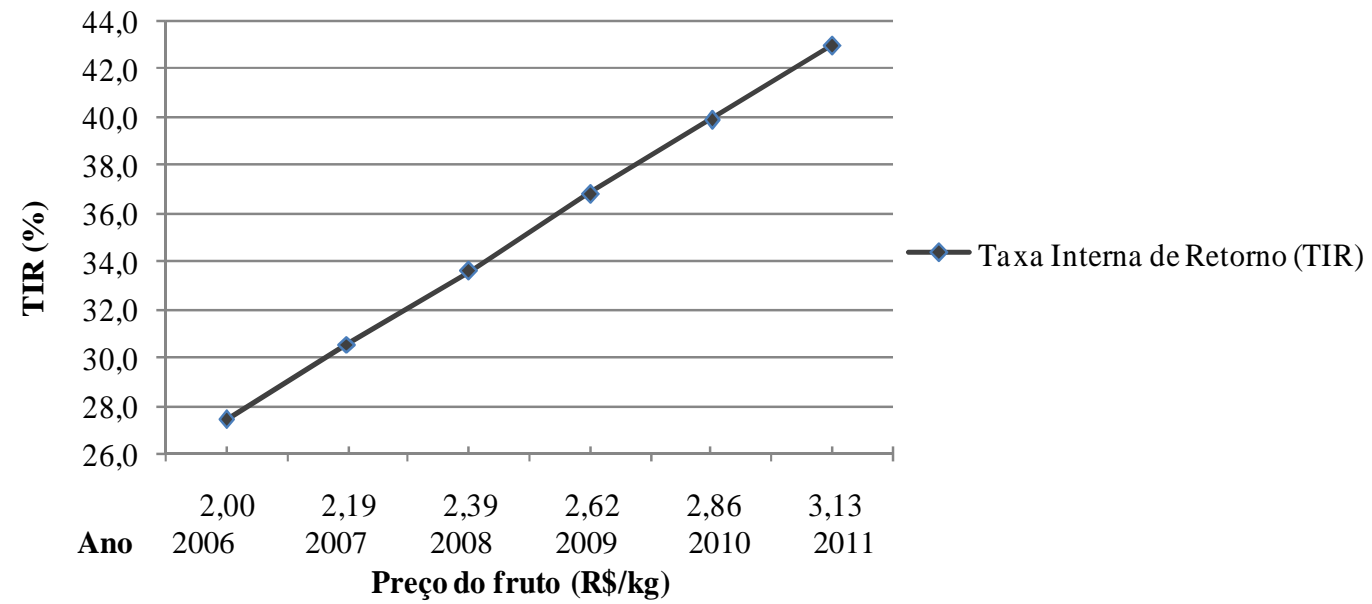

Fonte: Elaborado pelos autores.

Figura 4. Sensibilidade da TIR ao aumento nos níveis de preço do fruto seco - plantios de nim na região oeste do estado da Bahia.

Figure 4. IRR sensitivity of the reduction in the levels of price of the nut - neem plantations in the western region of Bahia state.

Sensibilidade aos custos totais de produção

Para a sensibilidade da taxa interna de retorno mediante a oscilação do custo total de produção, aumentaram-se tais custos em 10\%, 20\%, 30\%, 40\% e 50\% para ambas as regiões estudadas. Não há a necessidade de avaliação de sensibilidade com reduções de custos, uma vez que, a custos atuais, a cultura 
já é viável do ponto de vista econômico. O que se espera dessa análise de sensibilidade é determinar até que ponto os custos podem se elevar, mantendo a TIR da cultura ainda viável. figura 5 .

A sensibilidade-custo de produção para a região noroeste de São Paulo pode ser observada na

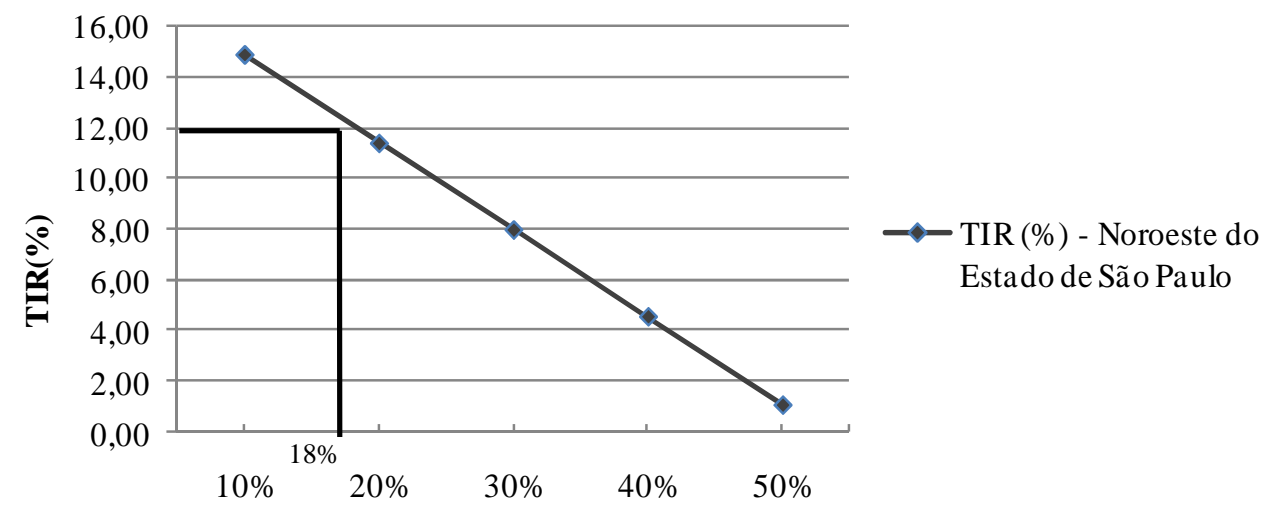

Aumento nos custos totais

Fonte: Elaborado pelos autores.

Figura 5. Sensibilidade da TIR ao aumento dos custos totais de produção para cultivos de nim indiano na região noroeste do estado de São Paulo.

Figure 5. IRR sensitivity of the increase in total production costs for crops of neem in the northwestern state of Sao Paulo.

Atendendo ao objetivo de determinar o limite de aumento de custos que a cultura pode suportar mantendo-a ainda viável economicamente, constatou-se que aumentos superiores a $18 \%$ inviabilizam a produção na região noroeste do estado de São Paulo. Uma análise dessa natureza permite ao produtor rural estimar quantitativamente o impacto (positivo ou negativo) na viabilidade econômica da cultura decorrente do aumento ou redução no valor de determinado insumo. A figura 6 apresenta a mesma variação nos custos para a região oeste da Bahia.

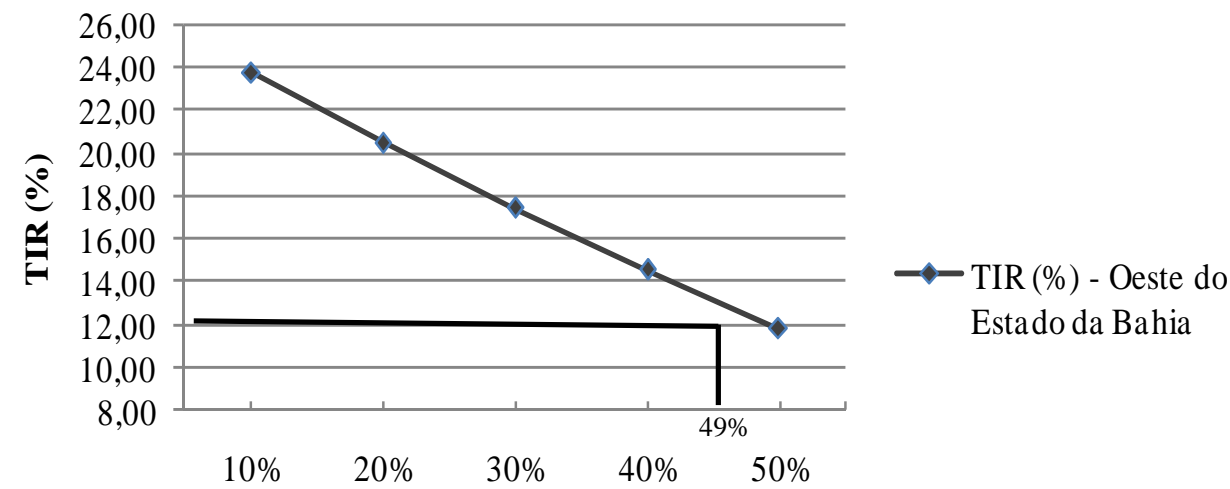

Fonte: Elaborado pelos autores.

Aumento nos Custos Totais

Figura 6. Sensibilidade da TIR ao aumento dos custos totais de produção para cultivos de nim indiano na região oeste do estado da Bahia.

Figure 6. IRR sensitivity of the increase in total production costs for indian cultures of neem in the western region of Bahia state. 
O aumento dos custos de produção da região oeste da Bahia não afeta a rentabilidade do cultivo de nim tal qual na região noroeste de São Paulo. Nesta última, um aumento de $18 \%$ nos custos torna a atividade inviável, enquanto na região oeste da Bahia apenas um aumento de $49 \%$ nos custos torna a TIR menor que a TMA, deixando a atividade inviável economicamente (Figura 6).

\section{CONCLUSÕES}

- Considerando uma taxa mínima de atratividade de $12 \%$ ao ano, os plantios de nim indiano para as duas regiões estudadas, em todos os cenários propostos, foram considerados viáveis na análise econômica.

- A região oeste da Bahia foi a que apresentou os melhores resultados econômicos, principalmente em razão do menor custo da terra, da maior produtividade e da condução da espécie utilizando-se todo o seu potencial produtivo (folhas, frutos e madeira).

- Os cenários que propuseram a compra da terra nas duas regiões estudadas apresentaram os menores retornos econômicos. No oeste baiano, a redução no retorno do investimento, quando comparada ao cenário em que não se remunera a terra, foi pequena. Sabendo-se que a terra dificilmente sofrerá depreciação e sendo o valor dela relativamente baixo, pode-se adquiri-la sem alterar significativamente o retorno do investimento. Esse modo de pensar não pode ser aplicado para a região noroeste de São Paulo, uma vez que nos cenários propostos a variação da TIR foi considerável.

- A análise de sensibilidade com base nos preços reais do quilo do fruto nos últimos quatro anos mostrou que reduções nos preços deste, que é o principal componente das receitas da cultura, podem tornar o investimento pouco atrativo no curto prazo, tanto na região noroeste de São Paulo quanto na região oeste da Bahia, quando comparados à TMA de $12 \%$ ao ano utilizada nas análises.

- A análise de sensibilidade com base nos custos de produção mostrou que o cultivo de nim na região noroeste de São Paulo apresenta-se bastante sensível a variações nos custos totais de produção. Na região oeste da Bahia essa sensibilidade é menor.

\section{REFERÊNCIAS}

BERGER, R.; PADILHA, J. B. Economia Florestal. Curitiba, PR, 2005, Editora UFPR.

BERGER, R., PADILHA, J. B. Economia Florestal. Curitiba: Editora UFPR, 2005.

BITTENCOURT, A. M. O cultivo do nim indiano (Azadirachta indica A. Juss.): uma visão econômica. Dissertação (Mestrado em Ciências Florestais). 147 f. Programa de Pós-Graduação em Engenharia Florestal. Universidade Federal do Paraná. Curitiba, 2006.

CASSAROTO FILHO, N.; KOPITTKE, B. H. Análise de Investimentos. 9. ed. São Paulo: Atlas, 2000.

CHATURVEDI, R.; RAZDAN, M. K.; BHOJWANI, S. S. In vitro clonal propagation of an adult tree of neem (Azadirachta indica A. Juss) by forced axillary branching. Plant Science, Clare, v. 166, n. 2, p. 501-506, 2004.

CODEVASF. Companhia de Desenvolvimento dos Vales do São Francisco e do Parnaíba. Diagnóstico Participativo Barreiras. Disponível em: <http://www.codevasf. gov.br> Acesso em: 15/10/2005.

EMPRESA BRASILEIRA DE PESQUISA AGROPECUÁRIA - EMBRAPA Desenvolvimento de tecnologias para a produção sustentável do Nim (Azadirachta indica A. Juss) e sua utilização como inseticida natural no âmbito da agricultura familiar. Projeto Nim. CNPF. Colombo - PR, 2005. 56 p.

EMATER. Instituto de Assistência Técnica e Extensão Rural do Estado do Rio Grande do Norte. Nim Inseticida Orgânico. Disponível em: 〈http://www.emater.rn.gov.br/artigos.asp?cod=57〉 . Acesso em: 08/01/2006.

FALESI, I. C.; FERREIRA, C. A. P.; CARVALHO, R. A. Análise econômica da produção do Nim indiano no Estado do Pará. Belém: Embrapa Amazônia Oriental. 2000, 4 p. (Comunicado Técnico, n. 43). 
GRAÇA, L. R.; MENDES, J. B. Análise econômica de sistemas de reflorestamento com bracatinga. Curitiba, PR. Boletim de Pesquisa Florestal, Colombo, v. 14, p. 54-63, 1987.

GRAÇA, L. R.; RODIGHERI, H. R.; CONTO, A. J. de. Custos florestais de produção: conceituação e Aplicação. Colombo: Embrapa Florestas, 2000. 32 p.

MARTINEZ, S. S. (Ed.). O Nim - Azadirachta indica: natureza, usos múltiplos, produção. Londrina: IAPAR, 2002. $142 \mathrm{p}$.

NEEM FOUNDATION. Economic Benefits of Neem Production. Disponível em: <http://www.neemfoundation.org/economic\%20potential.htm> Acesso em: 08/01/2006.

NEVES, E. J. M. Importância dos fatores edafo-climáticos para o uso do Nim (Azadirachta indica A. Juss) em programas florestais e agroflorestais nas diferentes regiões do Brasil. Colombo: Embrapa Florestas, 2004., p. 99-107. (Boletim de Pesquisa Florestal, n. 49).

PONCIANO, N. S.; MATA, P. M.; COSTA, H. T. Análise de viabilidade econômica e de risco da fruticultura na região norte Fluminense. Revista de Economia e Sociologia Rural, Brasília, DF, v. 42, n. 4, p. 615-635, oct./dec. 2004.

REZENDE, J. L. P.de; OLIVEIRA, A. D de. Análise econômica e social de projetos florestais. Viçosa. Universidade Federal de Viçosa, 2001. 389 p.

ROSS, S. A.; WESTERFIELD, R. W.; JAFFE, J. F. Administração Financeira. Tradução de Antonio Zorato Sanvicente. São Paulo: Atlas, 2002.

SOUZA DE, H. R. O impacto da Irrigação sobre o Desenvolvimento do Semi-Árido Nordestino: situação atual e perspectivas. Revista Econômica do Nordeste, Fortaleza, v. 21, n. 3/4, jul./dez. 1990.

THOROE, C. Making money by planning. In: IUFRO INTERNATIONAL CONFERENCE, 3., 1996, Pushkino. [Annals...] Gottingen: Cuvillier, 1997. 213 p.

XIN, T.; WEGENER, M. Developing a Sustainable Neem Industry in China. In: Annual Conference of the Association for Chinese Economics Studies, 16., 2004, Brisbaine. Proceedings of the... Brisbaine: ACESA, 2004. 